\title{
Hyperoxygenation Treatment Reduces Beta-amyloid Deposition via MeCP2-dependent Upregulation of MMP-2 and MMP-9 in the Hippocampus of Tg-APP/PS1 Mice
}

\author{
Juli Choi ${ }^{1}$, Hyejin Kwon ${ }^{1}$ and Pyung-Lim Han ${ }^{1,2 *}$ \\ ${ }^{1}$ Departments of Brain and Cognitive Sciences and ${ }^{2}$ Chemistry and Nano Science, \\ Ewha Womans University, Seoul 03760, Korea
}

\begin{abstract}
Recently we reported that hyperoxygenation treatment reduces amyloid-beta accumulation and rescues cognitive impairment in the Tg-APP/PS1 mouse model of Alzheimer's disease. In the present study, we continue to investigate the mechanism by which hyperoxygenation reduces amyloidbeta deposition in the brain. Hyperoxygenation treatment induces upregulation of matrix metalloproteinase-2 (MMP-2), MMP-9, and tissue plasminogen activator (tPA), the endopeptidases that can degrade amyloid-beta, in the hippocampus of Tg-APP/PS1 mice. The promoter regions of the three proteinase genes all contain potential binding sites for $\mathrm{MeCP} 2$ and Pea3, which are upregulated in the hippocampus after hyperoxygenation. Hyperoxygenation treatment in HT22 neuronal cells increases MeCP2 but not Pea3 expression. In HT22 cells, siRNA-mediated knockdown of Mecp 2 decreases Mmp- 9 expression and to a lesser extent, Mmp-2 and $t P A$ expression. In mice, siRNA-mediated Mecp 2 knockdown in the hippocampus reduces Mmp-9 expression, but not significantly Mmp-2 and $t P A$ expression. The ChIP assay indicates that hyperoxygenation treatment in Tg-APP/PS1 mice increases MeCP2 binding to the promoter regions of Mmp-2,Mmp- 9 and $t P A$ genes in the hippocampus. Together, these results suggest that hyperoxygenation increases the expression of MMP-2, MMP-9, and PA, of which MMP-9 is upregulated via MeCP2 in neuronal cells, and MMP-2 and tPA are upregulated through MeCP2 and other nuclear factors.
\end{abstract}

Key words: Hyperoxygenation, Beta-amyloid, MeCP2, MMP-2, MMP-9

\section{INTRODUCTION}

Alzheimer's disease (AD) is a progressive neurodegenerative disease characterized by extracellular amyloid- $\beta$ deposition and neuronal neurofibrillary tangle formation [1-3]. Aging is the most potent non-genetic risk factor for $\mathrm{AD}$ [4-6]. Brain aging is associated with decreased microvascular density [7-9], which can reduce oxygen $\left(\mathrm{O}_{2}\right)$ availability in the brain $[8,10]$. Reduction of cerebral blood flow and vascular hemodynamic function could affect the pathogenesis of AD [11-13]. Hypoxia conditions ag-

\footnotetext{
Submitted May 15, 2021, Revised August 14, 2021, Accepted August 15,2021

* To whom correspondence should be addressed. TEL: 82-2-3277-4130, FAX: 82-2-3277-3419 e-mail:plhan@ewha.ac.kr
}

gravate $\beta$-amyloid neurotoxicity in cultured neurons [14], increase $\beta$-amyloid accumulation, induce dendritic atrophy in hippocampal neurons, and produce cognitive impairment [13,15-18]. Patients with obstructive sleep apnea, a chronic condition characterized by intermittent hypoxemia during sleep [19], and patients with cardiac arrest [20] have elevated $\beta$-amyloid levels in serum. The results of these studies suggest that hypoxic states increase $\beta$-amyloid load and produce functional and structural changes related to $\mathrm{AD}$ pathology. However, the detailed mechanism by which decreased oxygen availability regulates $\mathrm{AD}$ pathology is not clearly understood.

Several lines of evidence suggest that hyperoxygenation treatment ameliorates $\mathrm{AD}$ pathology and improves cognitive behaviors in $\mathrm{AD}$ mouse models $[21,22]$. Hyperoxygenation treatment with $100 \% \mathrm{O}_{2}$ at 2 atmospheres absolute (ATA) for $60 \mathrm{~min}$ daily for 14
Copyright ( Experimental Neurobiology 2021. www.enjournal.org
This is an Open Access article distributed under the terms of the Creative Commons Attribution Non-Commercial License (http://creativecommons.org/licenses/by-nc/4.0) which permits unrestricted non-commercial use, distribution, and reproduction in any medium, provided the original work is properly cited. 
days in 3xTg-AD mice at 17 months of age reduced $\beta$-amyloid accumulation, attenuated neuroinflammatory processes, and improved cognitive impairment [23]. Hyperoxygenation treatment with $100 \% \mathrm{O}_{2}$ at 2 ATA for 60 min daily for 14 days in Tg-APP/ PS1 mice at 8 months of age also reduced $\beta$-amyloid accumulation, increased brain derived neurotrophic factor (BDNF) expression in the hippocampus, and rescued cognitive impairment [22]. Thus, hyperoxygenation treatment reverses key aspects of AD pathology. However, the detailed mechanisms by which hyperoxygenation decreases $\beta$-amyloid accumulation and improves structural and functional deficits remain largely unknown.

Beta-amyloid accumulation is regulated by the balance of $\beta$-amyloid production and clearance. Increased expression of amyloid protein precursor (APP), $\beta$-secretase $1 / 2$ (BACE1/2), presenilin-1/2 (PSEN1/2), or ApoE $\varepsilon 4$ may promote amyloidogenesis, whereas enhanced expression of $\beta$-amyloid clearance factors may reduce amyloidogenesis [24-26]. Beta-amyloid clearance can be regulated by $\beta$-amyloid degrading enzymes, including insulindegrading enzyme (IDE), neprilysin (NEP), matrix metalloproteinases 2 and 9 (MMP-2/9), and tissue/urokinase plasminogen activators (tPA/uPA) [27]. Therefore, rebalancing the expression of cellular factors that decrease $\beta$-amyloid production or those that promotes $\beta$-amyloid clearance could be a therapeutic strategy for AD treatment [26].

In the present study, we investigated the mechanism by which hyperoxygenation reduced $\beta$-amyloid accumulation in the brain of Tg-APP/PS1 mice, and demonstrated that hyperoxygenation treatment increased the expression of MMP-2, MMP-9, and tPA, the proteases that can degrade amyloid-beta proteins and promote amyloid-beta clearance in the brain.

\section{MATERIALS AND METHODS}

\section{Animals}

$\mathrm{APP}_{\text {SWE }} / \mathrm{PS} 1 \mathrm{dE} 9$ transgenic mice (Tg-APP/PS1 for short) overexpressing human $\mathrm{APP}_{\mathrm{SWE}}$ and PSEN1dE9 genes were described in previous studies [22, 28, 29]. Tg-APP/PS1 mice were crossed with $\mathrm{C} 57 \mathrm{BL} 6 \times \mathrm{C} 3 \mathrm{H}$ hybrid mice. After weaning, males and females were separately housed with 2 3 animals per cage under a 12-h light/dark cycle (lights on at $7 \mathrm{AM}$ and off at $7 \mathrm{PM}$ ) in a humidity (50 60\%)- and temperature $\left(22 \sim 24^{\circ} \mathrm{C}\right)$-controlled and specific pathogen-free (SPF) conditioned animal room.

Genotypes were determined by genomic PCR using the following primers; 5'-CTAGGCCACAGAATTGAAAGATCT-3' and 5'-GTAGGTGGAAATTCTAGCATCATCC-3' for WT (324 bp), 5'-AATAGAGAACGGCAGGAGCA-3' and 5'-GCCATGAGGGCACTAATCAT-3' for the PS1 gene (324/608 bp), and
5'-AGGACTGACCACTCGACCAG-3' and 5'-CGGGGGTCTAGTTCTGCAT-3' for the APP gene (324/350 bp).

Tg-APP/PS1 mice were maintained and handled in accordance with the Animal Care Guidelines of the Ewha Womans University (IACUC 19-016).

\section{Hyperoxygenation treatment in mice}

Hyperoxygenation treatment was carried out as described previously $[22,30]$. Briefly, seven-month-old Tg-APP/PS1 mice and their littermates were randomly assigned to hyperoxygenation and control groups. Briefly, mice in clear plastic mini-cages $(18 \times 12 \times 14$ $\mathrm{cm}$ ) were placed in a hyperbaric chamber (Particla Ltd., Daejeon, South Korea), supplying 100\% oxygen at 2.0 atmospheres absolute (ATA) for 60 min daily for 28 days. The $100 \% \mathrm{O}_{2}$ condition was slowly achieved by supplying $100 \% \mathrm{O}_{2}$ at $5 \mathrm{~L} / \mathrm{min}$ until the pressure reached 2.0 ATA in a 15-min period, followed by replenishing with $100 \% \mathrm{O}_{2}$ at $1 \mathrm{~L} / \mathrm{min}$ for $60 \mathrm{~min}$. The $100 \% \mathrm{O}_{2}$ was drained by decompressing the chamber pressure at $1.5 \mathrm{~L} / \mathrm{min}$ for $40 \mathrm{~min}$. Hyperoxygenation treatment started at 10:00 AM every day. The oxygen levels and pressure inside the chamber were monitored with an oxygen sensor and a pressure indicator until the end of each experiment.

\section{ELISA for insoluble Aß fractions}

ELISAs for $A \beta(1-42)$ levels were carried out as previously described $[22,31]$. In brief, the parietal cortex and hippocampus were separately homogenized in Tris-buffered saline $(20 \mathrm{mM}$ Tris-Cl, $137 \mathrm{mM} \mathrm{NaCl}, \mathrm{pH}$ 7.6) containing a proteinase inhibitor cocktail (11836153001; Roche Ltd., Indianapolis, IN, USA), followed by sonication on ice with 15 -sec pulses and 30-sec intervals, repeated three times using an EpiShear Probe Sonicator (Active Motif, Carlsbad, CA, USA) at $40 \%$ power outlet. The homogenates were centrifuged at $100,000 \mathrm{~g}$ at $4^{\circ} \mathrm{C}$ for $1 \mathrm{~h}$. The pellet, including insoluble proteins, was resuspended in ice-cold $70 \%(\mathrm{v} / \mathrm{v})$ formic acid and sonicated under the conditions described above. After incubating on ice for $30 \mathrm{~min}$, the homogenates were centrifuged at $100,000 \mathrm{~g}$ at $4^{\circ} \mathrm{C}$ for $1 \mathrm{~h}$. The supernatant was collected and neutralized with $1 \mathrm{M}$ Tris- $\mathrm{HCl}$ buffer (pH 11) at a 1:20 dilution, and the diluted formic acid extract was used for the ELISAs for formic acid-extractable $A \beta$. $A \beta(1-42)$ levels were measured using of the A $\beta 42$ ELISA kit (KHB3442; Invitrogen, Camarillo, CA, USA), following the manufacturer's instructions.

\section{Quantitative real-time PCR}

Quantitative real-time PCR analysis was carried out as described previously $[22,32]$. Briefly, total RNA was isolated from tissue homogenates or HT22 cells using the TRIzol reagent (15596-018, 
Invitrogen). Two $\mu \mathrm{g}$ of total RNA were treated with DNAse I and then converted into cDNA using a reverse transcriptase system (Promega, Madison, WI, USA). Real-time PCR was performed using the SYBR Green Supermix system (Bio-Rad Laboratories, Foster City, CA) and the following reagents in a volume of $20 \mu \mathrm{l}$ : $4 \mu \mathrm{l}$ of cDNA ( $1 / 8$ dilution of the converted cDNA), $10 \mu \mathrm{l}$ of $2 \mathrm{X}$ iQTM SYBR Green Supermix (Bio-Rad Laboratories), and $1 \mu \mathrm{l}$ each of $5 \mathrm{pmol} / \mu \mathrm{l}$ forward and reverse primers. PCR was carried out using the CFX 96 Real-Time PCR System Detector (Bio-Rad Laboratories) and the signals were normalized against the quantity of Gapdh.

The primers used were: Adam 10, forward 5'-AGCAACATCTGGGGACAAAC-3' and reverse 5'-TGGCCAGATTCAACAAAAC-3'; Apoe, forward 5'-GCTCCCAAGTCACACAAGAA-3' and reverse 5'-GTCGGTTGCGTAGATCCTC-3'; Bace 1, forward 5' -TCAAGATGGACTGCAAGGAGA-3' and reverse 5'-AAAATGTTCCAAGGGGTCGT-3'; Bace2, forward 5'-GTATAACGCAGACAAGGCCA-3' and reverse 5'AGAATTTGTCCAGCATGCCA-3'; Ide, forward 5'TTCGATGTTTCCCATGAACA-3' and reverse 5'-ACAGGAAAAACTGCGCAAAC-3'; Lrp 1, forward 5'-CGACATTGACGACAGGATCT-3' and reverse 5'-CACGATCTTGCTATCCACCA-3'; $M m p-2$, forward 5' -ATGATGATGAGCTGTGGACC-3'

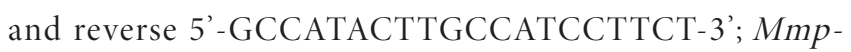
9, forward 5'-AGAGGCATACTTGTACCGCT-3' and reverse 5' -TCCCACTTGAGGCCTTTGAA-3'; Mecp2, forward 5'-ACAGCGGCGCTCCATTATC-3' and reverse 5'-CCCAGTTACCGTGAAGTCAAAA-3'; Nep, forward 5'-GGGAGGCTTTATGTGGAAGC-3' and reverse 5'-CCGGATtTGTGCAATCAAGT-3'; Pea3, forward 5'-TTGTTCCTGATTTCCATTCAGA-3' and reverse 5'-GACTCTGGGGTTCCTTCTTGA-3'; Psen 1, forward 5' -CGTGCTCTGCTAGCTTTGAC-3' and reverse 5'-GCTCTGTTTGGTTCACCTCA-3'; Psen2, forward 5'-GGAGAGCGAAGAAGACTGTG-3' and reverse 5'-GCCCGTTCTTCTCAGTGTAG-3'; Runx2, forward 5'-CCGGCCACTTCGCTAACTT-3' and reverse 5'-TGGTGCTCGGATCTACAGGAA-3'; $t P A$, forward 5'-GCGAACCAAGATGCTTCAAT-3' and reverse 5'-CTCCTTGCATTGTAGGGCTT-3'; uPA, forward 5'-ATGTGCAGATTGGCCTAAGG-3' and reverse 5'-TTCTTCTGGTAGATGGCTGC-3'; and Gapdh, forward 5'-AGAAGGTGGTGAAGCAGGCATC-3' and reverse 5'-CGAAGGTGGAAGA GTGGGAGTTG-3'.

\section{Western blotting analysis}

Immunoblot analyses were carried out as described previously
$[22,32]$. Briefly, brain tissues were homogenized in an ice-cold homogenization buffer (50 mM Tris-HCl, pH 8.0, $150 \mathrm{mM} \mathrm{NaCl}, 1 \%$ Nonidet P-40, 0.1\% SDS, and 0.1\% sodium deoxycholate) containing a protease inhibitor cocktail (Roche) by sonication on ice using an EpiShear Probe Sonicator at 40\% power (Active Motif) with 15sec pulses. After incubation on ice for $30 \mathrm{~min}$, the homogenate was centrifuged at $13,000 \times \mathrm{g}$ at $4{ }^{\circ} \mathrm{C}$ for $15 \mathrm{~min}$, and the supernatant was collected. Protein concentration for each sample was determined by the Bradford method (Bio-Rad Laboratories). Twenty $\mu \mathrm{g}$ of proteins per sample were solved in $30 \mu \mathrm{l}$ of a $6 \mathrm{X}$ sample loading buffer and boiled for $5 \mathrm{~min}$. Protein samples were loaded on each lane of SDS-PAGE gels, and resolved proteins on the gels were transferred onto a PVDF membrane using the Trans-Blot ${ }^{\circledR} \mathrm{SD}$ System and PowerPac" Power Supply System (\#1703848, Bio-Rad). The following primary antibodies were used: rabbit polyclonal $\beta$ APP (51-2700, Zymed Laboratories, Camarillo, CA, USA), goat polyclonal APOE (sc-6384, Santa Cruz Biotechnology), rabbit monoclonal BACE1 (ab183612, Abcam, Cambridge, MA, USA), rabbit monoclonal GFAP (12389, Cell Signaling, Danvers, MA, USA), rabbit polyclonal Iba-1 (019-19741, Wako, Osaka, Japan), rabbit polyclonal IDE (97-273, Millipore, Billerica, MA, USA), rabbit monoclonal MeCP2 (3456S, Cell Signaling), mouse monoclonal MMP-2 (MS-567, Thermo Fisher Scientific, Runcron, Chesire, UK), rabbit polyclonal MMP-9 (AB13458, Millipore, Billerica, MA, USA), goat polyclonal NFkB p65 (sc-372, Santa Cruz Biotechnology), rabbit monoclonal p-NFkB p65 (3003, Cell Signaling), rabbit polyclonal p38 (sc-535, Santa Cruz Biotechnology), rabbit monoclonal p-p38 (4511, Cell Signaling), rabbit polyclonal Pea3 (ab189826, Abcam), mouse monoclonal PSEN1 (MAB5232, Millipore), rabbit polyclonal tPA (sc-15346, Santa Cruz Biotechnology), rabbit polyclonal uPa (sc-14019, Santa Cruz Biotechnology), and mouse monoclonal $\beta$-actin antibody (sc-47778, Santa Cruz Biotechnology).

The following secondary antibodies were used: donkey anti-goat IgG (sc-2056, Santa Cruz Biotechnology), goat anti-mouse IgG (GTX213111, GeneTex, Irvine, CA, USA), and goat anti-rabbit IgG (GTX213110, GeneTex).

\section{Immunohistochemical analyses}

Immunohistochemical analyses were carried out as described previously $[22,33]$. Briefly, mice were anesthetized with $2.5 \%$ avertin $(20 \mu \mathrm{g} / \mathrm{g}$ body weight, i.p.). and then transcardially perfused with $0.9 \%$ saline, followed by $4 \%$ paraformaldehyde in 0.1 $\mathrm{M}$ phosphate buffer (PBS; $137 \mathrm{mM} \mathrm{NaCl}, 2.7 \mathrm{mM} \mathrm{KCl}, 10 \mathrm{mM}$ $\mathrm{Na}_{2} \mathrm{HPO}_{4}, 1.8 \mathrm{mM} \mathrm{KH} \mathrm{PO}_{4}, \mathrm{pH}$ 7.4). Brains were surgically obtained and incubated in $4 \%$ paraformaldehyde buffer at $4^{\circ} \mathrm{C}$ for an additional $24 \mathrm{~h}$. Brains were coronally cut with a $40-\mu \mathrm{m}$-thickness 
using a vibratome (Leica VT 1000S, Leica instruments, Mussloch, Germany).

Floating sections were treated with $3 \%$ hydrogen peroxide in PBS at room temperature (RT) for $30 \mathrm{~min}$. They were then washed three times for $10 \mathrm{~min}$ each wash with PBS containing $0.1 \%$ Triton-X 100 (PBST). After blocking with 5\% bovine serum albumin (BSA) in PBST at RT for $1 \mathrm{~h}$, brain sections were incubated with primary antibody in $5 \% \mathrm{BSA}$ at $4{ }^{\circ} \mathrm{C}$ for $24 \mathrm{~h}$. Sections were rinsed three times with PBST and incubated with biotinylated goat anti-mouse secondary antibody (BA-9200, Vector Laboratories, Burlingame, CA, USA) or anti-rabbit secondary antibody (BA1100, Vector Laboratories) at a 1:200 dilution in PBST at RT for 1 h. After washing brain sections with PBST, stained signals were visualized using an ABC Elite kit (PK 6200, Vector Laboratories) and 3,3'-diaminobenzidine (D5637, Sigma-Aldrich) in 0.1 M Tris- $\mathrm{HCl}$ ( $\mathrm{pH}$ 7.4). Stained sections were mounted on a gelatin-coated slide glass with Canada balsam solution (1302; Yakuri Pure Chemical Co. LTD., Kyoto, Japan). For immunofluorescent-labeled staining, anti-rabbit secondary antibody labeled with DyLight594 (DI-1094, Vector Laboratories) were used. Stained sections were washed two times with PBST and rapidly mounted on a gelatin-coated slide glass with VECTASIELD ${ }^{\circledR}$ antifading mounting medium with DAPI (H-1200, Vector Laboratories). Stained sections were analyzed using an Olympus BX 51 microscope equipped with a DP71 camera, and stained images were analyzed using the MetaMorph Microscopy Automation \& Image Analysis software (Molecular Devices, Sunnyvale, CA, USA).

The following primary antibodies were used: monoclonal mouse Bam10 (A5213, Sigma-Aldrich, Saint Louis, MO, USA), rabbit monoclonal GFAP (12389, Cell Signaling), rabbit polyclonal Iba-1 (019-19741, Wako, Osaka, Japan), and monoclonal rabbit MeCP2 (3456S, Cell Signaling).

The thioflavin S (ThS) staining solution was prepared by dissolving to $1 \mathrm{mM}$ concentration in $50 \%$ ethanol, which was then filtered through a $0.22-\mu \mathrm{m}$ filter. To analyze the colocalization of microglia around plaques, brain sections were stained with Iba- 1 antibody as described above and mounted them onto a gelatin-coated slide glass. The Iba-1-stained sections were then incubated with a ThS solution for 7 min under a dark condition. The stained sections were washed in 100\%, 95\%, and 90\% ethanol solution for $30 \mathrm{sec}$ each, and then in $50 \%$ ethanol for 2 min to quench nonspecific binding of Ths. After rinsing with PBS for $30 \mathrm{sec}$ twice and lightly dried, the stained sections were coverslipped with an anti-fade fluorescent mounting medium (S3023, DAKO, Carpinteria, CA, USA). The stained images were photographed using an Olympus BX51 microscope equipped with a DP71 camera and a fluorescent filter set. All images were analyzed using MetaMorph Microscopy
Automation \& Image Analysis software (Molecular device).

\section{HT22 cell culture, PFD treatment, and transfection of siRNA}

HT22 mouse hippocampal cells were cultured as described previously $[22,34]$. Briefly, HT22 cells were cultured at $37^{\circ} \mathrm{C}$ under $5 \%$ $\mathrm{CO}_{2}$ in a growth media consisting of Dulbeccos modified Eagle's medium (DMEM; LM001-05, Welgene, Gyeongan-si, Korea) supplemented with $10 \%$ heat-inactivated fetal bovine serum (FBS; FB02-500, Serum Source International, Charlotte, NC, USA), penicillin (20 units/ml) and streptomycin (20 mg/ml) (LS020-02, Welgene).

When HT22 cells reached 70 80\% confluency, they were trypsinized and were plated at $1.0 \times 10^{5}$ cells/well in a 6 -well plate containing the growth media. After $24 \mathrm{~h}$, the media was changed with DMEM media containing 1\% FBS and no antibiotics with or without perfluorodecalin (PFD, P9900, Sigma-Aldrich, St. Louis, MO, USA) to deliver molecular oxygen and cultured for an additional $24 \mathrm{~h}$.

Transfection of siRNA into HT22 cells was carried out using Lipofectamine-2000 (13778-075; Invitrogen) as described previously [22]. HT22 cells were plated at $1.0 \times 10^{5}$ cells/well in a 6 -well plate containing the growth media. After $24 \mathrm{~h}$, the growth media was changed to DMEM containing 1\% FBS and no antibiotics. siRNA ( $3 \mu \mathrm{l}$ of $20 \mu \mathrm{M}$ siRNA) and Lipofectamine-2000 (9 $\mu \mathrm{l})$ were separately diluted in $150 \mu \mathrm{l}$ of Opti-MEM ${ }^{\circledR}$ Medium (31985070, Gibco-Thermo Fisher Scientific, Paisley, Scotland, UK). Diluted siRNA was mixed with diluted Lipofectamine-2000 at a 1:1 ratio (150 $\mu \mathrm{l} \mathrm{each)} \mathrm{and} \mathrm{incubated} \mathrm{for} 5 \mathrm{~min}$ at RT. The siRNA-Lipofectamine mix $(250 \mu \mathrm{l} /$ well $)$ was dripped onto HT22 cells in 6-well plates, and cells were grown with or without PFD for $24 \mathrm{~h}$.

\section{Chromatin immunoprecipitation assay}

Chromatin immunoprecipitation (ChIP) assays were carried out as described previously $[22,34]$ using a ChIP-IT ${ }^{\circledR}$ Express kit (102026, Active Motif). In brief, the hippocampus was surgically prepared. A total of 40 50 mg of hippocampal tissue prepared and pooled from $4 \sim 5$ animals was minced using a razor blade and immersed in $7 \mathrm{ml}$ of $1 \%$ formaldehyde (F1635, Sigma-Aldrich) in PBS for 8 min to crosslink proteins and DNA. The crosslinking reaction was stopped by adding $5 \mathrm{ml}$ of $0.125 \mathrm{M}$ glycine solution and incubating for $5 \mathrm{~min}$. After the addition of $5 \mathrm{ml}$ of lysis buffer, fixed tissues were homogenized using a Dounce homogenizer with the "A" pestle (PYREX ${ }^{\circledR}$ Dounce Tissue Grinders; Thomas Scientific, Swedesboro, NJ, USA). The homogenates were centrifuged at $1,250 \times \mathrm{g}$ at $4^{\circ} \mathrm{C}$ for $10 \mathrm{~min}$. The pellet containing the nuclei was collected, resuspended in $500 \mu \mathrm{l}$ of lysis buffer and homogenized 
using a Dounce homogenizer with the "B" pestle.

The homogenates were centrifuged at $1,250 \times \mathrm{g}$ at $4^{\circ} \mathrm{C}$ for $10 \mathrm{~min}$, and the pellet containing crosslinked chromatins was resuspended in $300 \mu \mathrm{l}$ of a shearing buffer containing proteinase cocktail and PMSF, and placed on ice. The fixed chromatins were sheared to $200 \sim 800$ bp in size by sonication on ice with 20 -sec pulses and 50 -sec rest intervals, repeated 20 times for hippocampal tissue samples using an EpiShear Probe Sonicator set to 35\% power (Active Motif). After centrifugation at $22,000 \times \mathrm{g}$ at $4{ }^{\circ} \mathrm{C}$ for $10 \mathrm{~min}$, the supernatant containing sheared chromatin was saved, and the DNA content was quantified using a NanoDrop machine (Thermo Fisher Scientific, Wilmington, DE, USA). Sheared chromatin samples were stored at $-80^{\circ} \mathrm{C}$ until use.

The sheared chromatin sample $(10 \mu \mathrm{l})$ was set aside to use as an input DNA control. For immunoprecipitation, $10 \mu \mathrm{g}$ of sheared chromatins was added to $2 \mu \mathrm{g}$ of anti-MeCP2 primary antibody (3456S; Cell Signaling), and $20 \mu$ of protein $G$ magnetic beads in $100 \mu \mathrm{l}$ of ChIP Buffer I containing a proteinase inhibitor cocktail (1X final) was rocked gently at $4{ }^{\circ} \mathrm{C}$ overnight. Non-immune rabbit IgG (ab37415; Abcam) was used as an antibody binding control.

While holding the sample tubes on a magnetic rack, the magnetic beads containing immunoprecipitates were washed with $200 \mu \mathrm{l}$ of ChIP buffer I, followed by $200 \mu$ of ChIP buffer II twice. After washing, the beads were resuspended in $50 \mu \mathrm{l}$ of elution buffer and incubated for $15 \mathrm{~min}$ at room temperature with gentle rocking. After adding $50 \mu \mathrm{l}$ of reverse cross-linking buffer and incubating at $95^{\circ} \mathrm{C}$ for $15 \mathrm{~min}$, the supernatant containing eluted chromatins was collected. The sheared chromatins $(10 \mu \mathrm{l})$ were mixed with 88 $\mu \mathrm{l}$ of ChIP buffer II and $2 \mu \mathrm{l}$ of $5 \mathrm{M} \mathrm{NaCl}$ and were incubated at $95^{\circ} \mathrm{C}$ for $15 \mathrm{~min}$. The reaction mixtures were then added with $1 \mu \mathrm{g}$ of Proteinase $\mathrm{K}$, incubated at $37^{\circ} \mathrm{C}$ for $1 \mathrm{~h}$, and then mixed with 2 $\mu$ of Proteinase K stop solution. The final reaction mixture (100 $\mu \mathrm{l})$ was used as immunoprecipitated DNA and used for real-time PCR. Immunoprecipitated DNA was used for quantitative realtime PCR.

One-tenth of the input DNA was used for quantitative PCR to control for the relative amount of DNA fragments in immunoprecipitation. Immunoprecipitated quantities were calculated by following the methods described previously $[22,34]$. ChIP-qPCR data were analyzed by normalization of the ChIP signal relative to that of the input DNA using the CFX 96 Real-Time PCR System Detector system (Bio-Rad Laboratories). Samples used for ChIP assays were obtained from more than two independent sets, and quantitative PCR was repeated in the indicated number of times.

The primers used were designed using the Ensemble Genome Browser (http://asia.ensembl.org/index.html), Primer3Web version 4.1 .0 (http://primer3.ut.ee/), and the analyzed primer pairs were designed using an in silico PCR program (the USCS Genome Browser at http://genome.cse.ucsc.edu/cgi-bin/hgPcr).

The following primer sets were used: Mmp-2, forward 5'-GGGGATGGGGAATGGAAGAA-3' and reverse 5'-CTGGATGCAGCGGAAACAAG-3' (-73 +81, from the transcription start site); Mmp-9, forward 5'-GTGTCTCAGAAGCCCAAGGA-3' and reverse 5'-TTGTGGGAAAGGGAAGGAGG-3' (-395 -259, from the transcription start site); and tPA, forward 5'-CATCTGCCCGGCCAATTAAT-3' and reverse 5'-GGAACTGTAAGGATCTGCTGC-3'(-405 -250, from the transcription start site).

\section{Stereotaxic injection of siRNA}

Stereotaxic injection of siRNA was performed as described previously $[22,32]$. In brief, mice were anesthetized with a mixture $(3.5: 1)$ of ketamine hydrochloride $(50 \mathrm{mg} / \mathrm{ml})$ and xylazine hydrochloride $(23.3 \mathrm{mg} / \mathrm{ml})$ at a dose of $2.5 \mu \mathrm{l} / \mathrm{g}$ body weight. One portion of diluted siRNA $(50 \mathrm{ng} / \mu \mathrm{l})$ was mixed with 2.5 portions Neurofect transfection reagent (T800075, Genlantis, San Diego, CA, USA), and 0.5 portion of $50 \%$ sucrose $20 \mathrm{~min}$ prior to injection and incubated on ice.

The siRNA mix (each, $1.8 \mu \mathrm{l}$ of $7.5 \mathrm{ng} / \mu \mathrm{l}$ ) was injected into the CA3 region (stereotaxic coordinate: AP, - 1.9; ML, \pm 3.0 ; DV, -2.1 $\mathrm{mm}$ ) on both sides using a stereotaxic injection system (Vernier Stereotaxic Instrument, Leica Biosystems, Wentzler, Germany) and a Hamilton syringe with a $30-\mathrm{G}$ needle. After $5 \mathrm{~min}$, the needle was removed in three intermediate steps for 3 min each. Mice were kept on a warm pad until awakened. Tissue samples with siRNA injection were prepared $48 \mathrm{~h}$ after injection.

Control siRNA (siCON, SN-1012) and MeCP2-siRNA (siMeCP2, 1385135; NM_001081979.2) were purchased from Bioneer Co. (Daejeon, Korea). The siRNAs were resolved to $50 \mathrm{ng} /$ $\mu \mathrm{l}$ in a siRNA dilution buffer (B-002000-UB-100, Dharmacon, Lafayette, CO, USA).

\section{Statistical analyses}

Two-sample comparisons were carried out using Student's $t$-test, and multiple comparisons were performed using one-way analysis of variance (ANOVA) followed by the Newman-Keuls post hoc test or two-way ANOVA followed by the Bonferroni post hoc test. GraphPad PRISM 6.0 software (GraphPad Software. Inc., CA, USA) was used for statistical analyses. All data are presented as mean \pm SEM, and statistical significance was accepted at $\mathrm{p}=0.05$.

\section{RESULTS}

\section{Hyperoxygenation treatment suppressed $\beta$-amyloid}


A

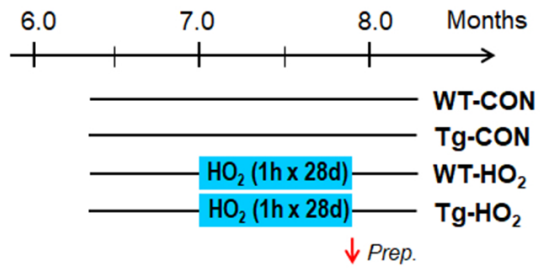

$\mathrm{HO}_{2}: 100 \%, 2.0 \mathrm{ATA}, 1 \mathrm{~h} \times 28 \mathrm{~d}$

B

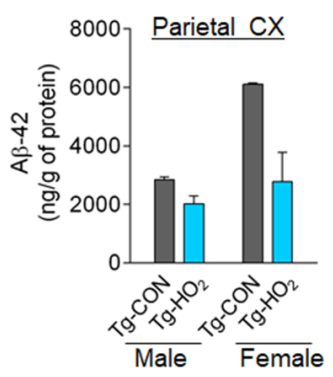

C

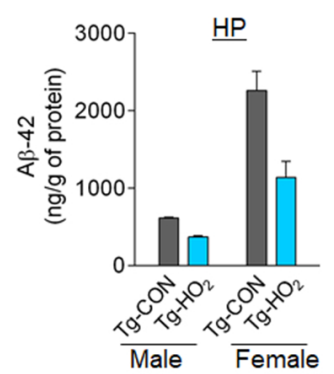

D
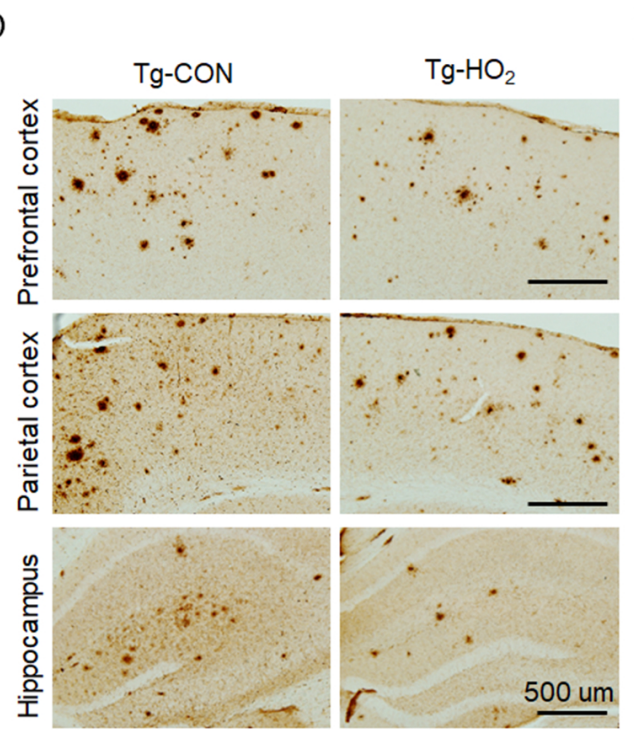

$E$
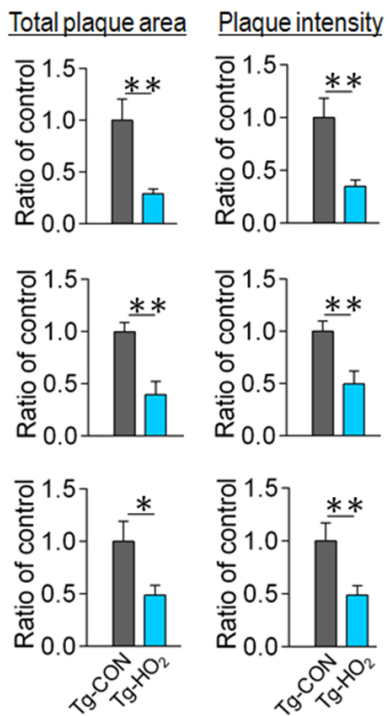

Fig. 1. Hyperoxygenation treatment suppressed beta-amyloid plaque deposition in the brain of APP/PS1-Tg mice. (A) Experimental design. Tg-APP/ PS1 mice at 7 months of age were exposed to $100 \% \mathrm{O}_{2}$ at 2 ATA for 60 min daily for 28 days. (B, C) ELISA data showing insoluble A $\beta(1-42)$ levels in the parietal cortex (B) and hippocampus (C) of Tg-APP/PS1 control mice (Tg-CON) and Tg-APP/PS1 mice exposed to hyperoxygenation $\left(\mathrm{Tg}-\mathrm{HO}_{2}\right)$. Male and female mice were separately examined. $\mathrm{n}=4 \sim 7$ animals/group, $6 \sim 8$ repeats. (D, E) Immunohistochemical images showing plaque deposition stained with Bam-10 anti-A $\beta$ antibody in the prefrontal cortex, parietal cortex, and hippocampus of Tg-CON and $\mathrm{Tg}_{-}-\mathrm{HO}_{2}(\mathrm{D})$. Quantification levels by total plaque areas (relative ratios of summed plaque area in $\mu^{2} / \mathrm{mm}^{2}$ ) and summed stained intensity (relative ratios of arbitral unit) were presented (E). $\mathrm{n}=5 \sim 7$ animals/group, 10 12 sections. Data are presented as mean \pm SEM. ${ }^{* * *}$ difference between indicated groups; ${ }^{*} \mathrm{p}<0.05 ;{ }^{* *} \mathrm{p}<0.01$ (Students $\mathrm{t}$-test).

\section{deposition in the brain of APP/PS1-Tg mice}

$\mathrm{Tg}$-APP/PS1 mice at 7 months of age were subjected to hyperoxygenation treatment $\left(100 \% \mathrm{O}_{2}, 2\right.$ ATA) for 60 min daily for 28 consecutive days (Fig. 1A). ELISA analysis revealed that hyperoxygenation treatment decreased amyloid-beta 42 (A $\beta 42)$ levels in the parietal cortex and hippocampus in both male and female Tg-APP/PS1 mice (Fig. 1B, 1C). Consistently, immunohistological staining with an anti-A $\beta$ antibody (Bam-10) indicated that hyperoxygenation treatment reduced $\beta$-amyloid deposition in all brain regions examined, including the prefrontal cortex, parietal cortex, and hippocampus (Fig. 1D, 1E).

\section{Hyperoxygenation treatment increased the expression of MMP-2, MMP-9, and tPA in the hippocampus of Tg-APP/ PS1 mice}

Among the cellular factors that potentially regulates $\beta$-amyloid production or clearance, we explored those whose expression are changed by hyperoxygenation. Real-time PCR analysis indicated that transcript levels of the genes regulating $\beta$-amyloid production, including Beta-secretase 1 (Bace1), Bace2, Presenilin-1 (Psen1), Psen2, ADAM metallopeptidase domain 10 (Adam10), and Apolipoprotein $E$ (Apoe) in the hippocampus were not changed by hyperoxygenation (Fig. 2A). Western blot analysis also showed that expression levels of APP, BACE1, PSEN1, and ApoE were not changed by hyperoxygenation (Fig. 2B, 2C). On the contrary, the transcript levels of the genes associated with amyloid-beta clearance, including Matrix metalloproteinases-2 (Mmp-2), Mmp-9, and tissue plasminogen activator ( $P A$ ), were upregulated in the hippocampus after hyperoxygenation (Fig. 2D), whereas the transcript levels of neprilysin (Nep), insulin-degrading enzyme (Ide) and low-density lipoprotein receptor-related protein-1 (LrpI) were not affected. Western blot analysis showed that hyperoxygenation treatment increased the expression of MMP-2 and MMP-9, whereas the effect of hyperoxygenation on the expression of tPA, uPA, and IDE was subtle or not significant (Fig. 2E, 2F).

\section{Hyperoxygenation suppressed inflammatory responses in the hippocampus of Tg-APP/PS1 mice}

Next, we examined whether hyperoxygenation treatment induces neuroinflammatory responses in the brain. Immunohistochemical analysis indicated that anti-GFAP staining levels in the hippocampus of Tg-APP/PS1 mice were enhanced compared to wildtype control, whereas hyperoxygenation treatment in Tg-APP/PS1 mice significantly reduced the increased anti-GFAP staining levels compared to those in non-treated Tg-APP/PS1 mice (Fig. 3A, 3B). Anti-Iba-1 staining levels in the hippocampus of Tg-APP/ 

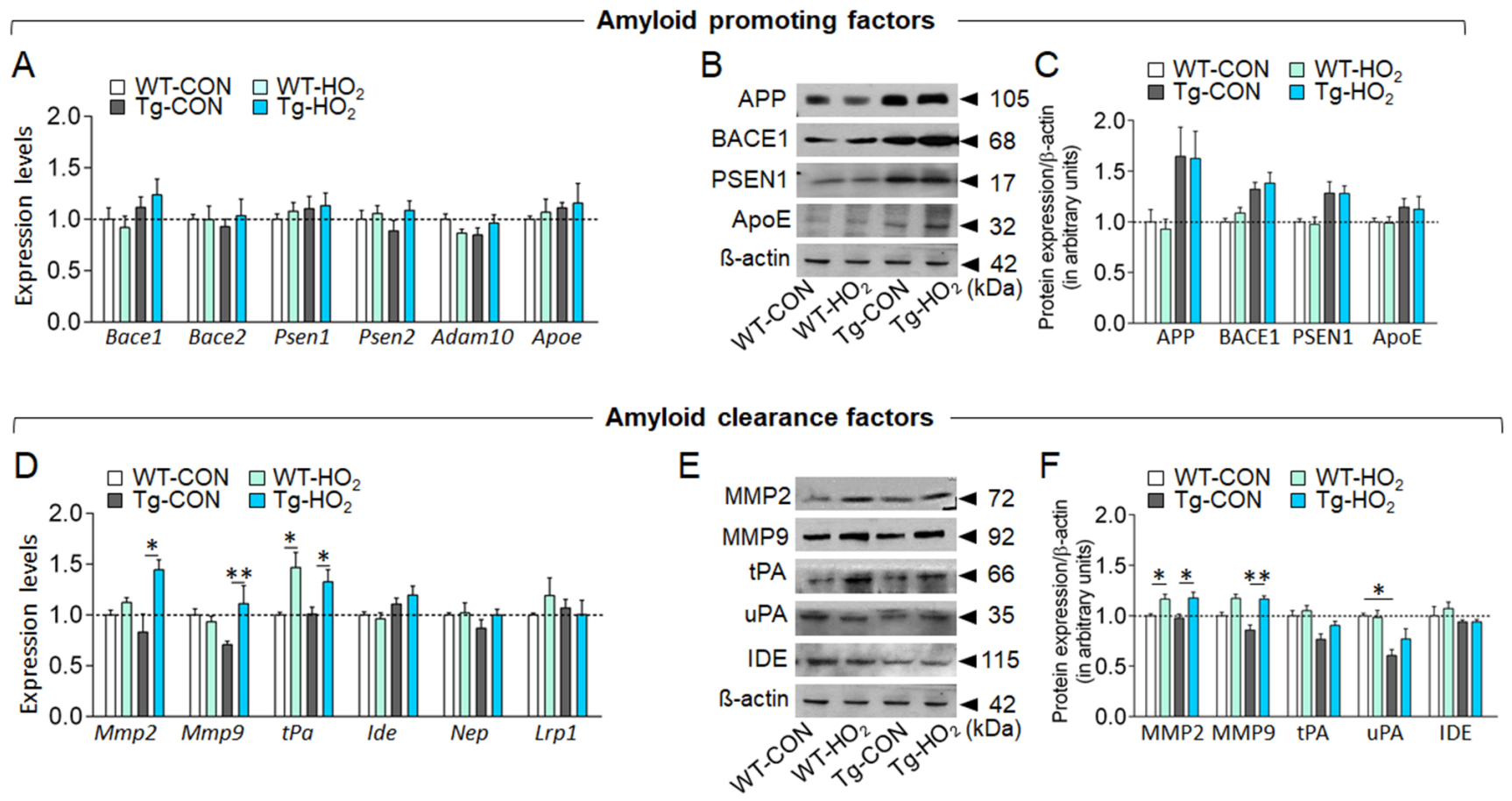

Fig. 2. Hyperoxygenation treatment increased the expression of MMP-2, MMP-9, and tPA in the hippocampus of Tg-APP/PS1 mice. (A) Real-time PCR data showing transcript levels of Bace1,Bace2, Psen1, Psen2, Adam10, and Apoe genes in the hippocampus of wildtype control (WT-CON), wildtype mice exposed to hyperoxygenation (WT- $\mathrm{HO}_{2}$ ), Tg-APP/PS1 control mice (Tg-CON), and Tg-APP/PS1 mice exposed to hyperoxygenation (Tg$\mathrm{HO}_{2}$ ). $\mathrm{n}=6-7$ animals/group, 4 PCR repeats. (C) Western blot data showing expression levels of APP, BACE1, PSEN1, and ApoE in the hippocampus of WT-CON, WT- $\mathrm{HO}_{2}$, Tg-CON, and Tg- $\mathrm{HO}_{2}$ mice. $\mathrm{n}=6 \sim 8$ animals/group, $4 \sim 11$ repeats. (D) Real-time PCR data showing transcript levels of $M m p-2$, Mmp-9, tPA, Ide, Nep, and Lrpl genes in the hippocampus of WT-CON, WT- $\mathrm{HO}_{2}$, Tg-CON, and Tg- $\mathrm{HO}_{2}$ mice. $\mathrm{n}=6 \sim 7$ animals, 4 data points. (E) Western blot data showing expression levels of MMP-2, MMP-9, tPA, uPA, and Ide genes in the hippocampus of WT-CON, WT-HO $2, \mathrm{Tg}^{-\mathrm{CON}}$, and Tg-HO mice. Tissue samples were prepared at the time point of Figure 1A. $n=6 \sim 8$ animals/group, $4 \sim 10$ data points. Data are presented as mean \pm SEM. ${ }^{* * *}$ difference between indicated groups. ${ }^{*} \mathrm{p}<0.05 ;{ }^{* *} \mathrm{p}<0.01$ (two-way ANOVA and Bonferroni post hoc test).

PS1 mice were increased compared to wildtype, whereas hyperoxygenation treatment in Tg-APP/PS1 mice significantly reduced the increased anti-Iba-1 staining levels compared to those in nontreated Tg-APP/PS1 mice (Fig. 3C, 3D). However, hyperoxygenation treatment in Tg-APP/PS1 mice did not reduce the levels of anti-Iba-1 staining surrounding $\beta$-amyloid plaques (Fig. 3E, 3F).

Western blot analysis indicated that the expression levels of phospho-NFkB (p65), phospho-p38, GFAP, and Iba-1 in the hippocampus and prefrontal cortex were enhanced in Tg-APP/ PS1 mice, whereas hyperoxygenation suppressed their increased expression (Fig. 3G, 3H). Together, these results suggest that hyperoxygenation treatment suppresses, rather than induces, proinflammatory responses in the brains of Tg-APP/PS1 mice.

\section{MePC2 regulated the expression of the Mmp-2 and Mmp-9 genes in HT22 neuronal cells}

We explored the nuclear factors that potentially upregulated the transcription of the Mmp-2,Mmp-9 and $t P A$ genes under hyperoxygenation. Examination of the promoter sequences of the genes using GeneCards (http://www.genecards.org) and PubMed literature searches indicated that the proximal promoter regions of the Mmp-2,Mmp- 9 and $t P A$ genes contain the cis-acting elements for the binding of Runx2, Pea3, NFkB, and/or Stat, which could act as transcription factors. We also found a stretch of $\mathrm{CpG}$ islands that are known to serve as binding sites for methyl-CpG binding protein (MeCP2) around the transcription initiation site (Fig. 4A).

Real-time PCR analysis indicated that transcript levels of Mecp2 and $P$ ea 3 , but not Runx2, in the hippocampus tended to decrease in the hippocampus of Tg-APP/PS1 mice. In contrast, hyperoxygenation treatment in Tg-APP/PS1 mice significantly increased the decreased expression of the Mecp2 and Pea3 (Fig. 4B, 4C). Western blot analysis indicated that hyperoxygenation treatment also increased the decreased expression of $\mathrm{MeCP} 2$ and Pea3 in Tg-APP/PS1 mice (Fig. 4D, 4E).

In HT22 hippocampal neuronal cells, siRNA-mediated knockdown of the Mecp2 reduced the expression of the Mmp-2 and Mmp-9, whereas the Mecp2 knockdown effect on the expression of the tPA and uPA was subtle or not significantly (Fig. 5A, 5B). In 

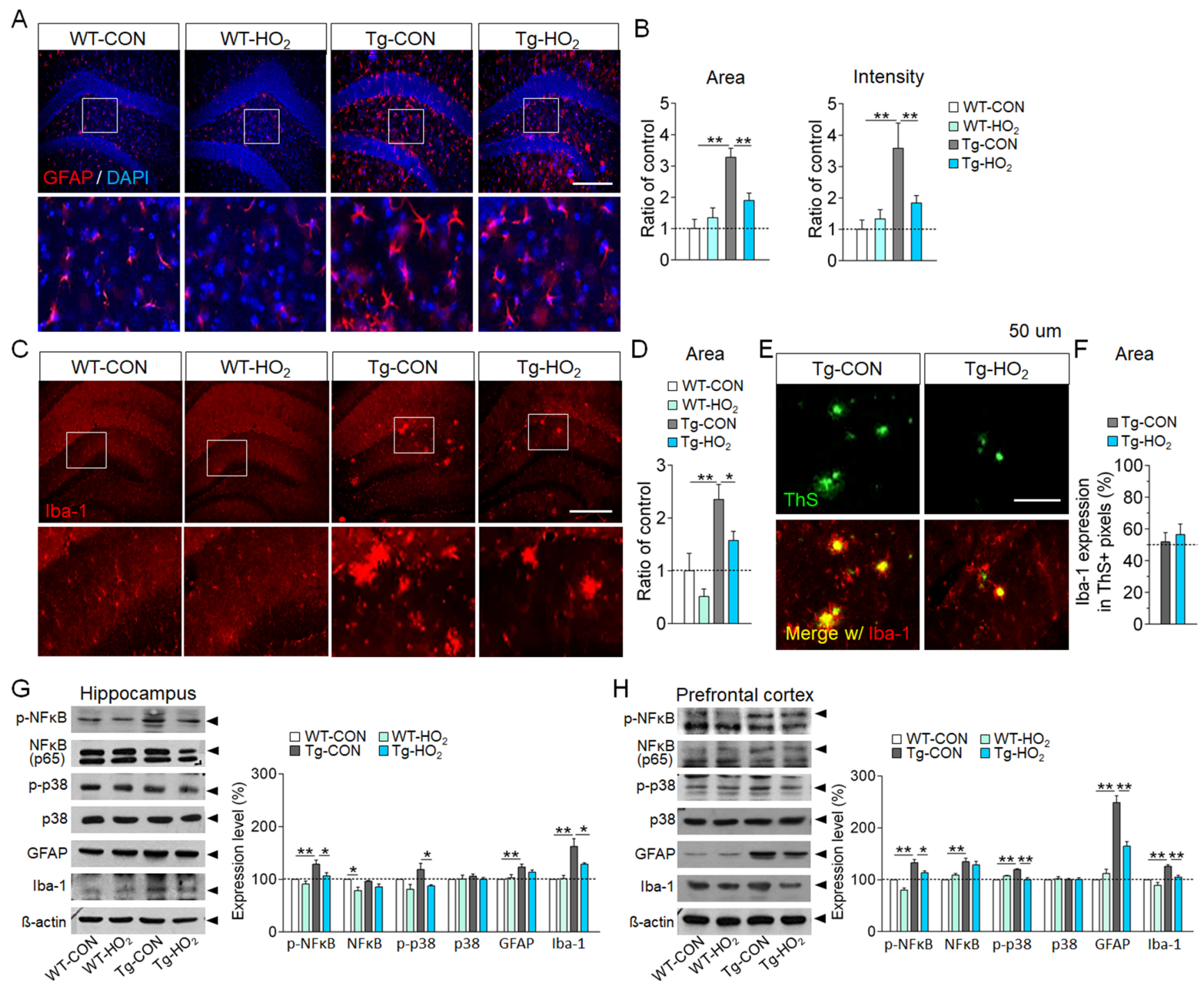

Fig. 3. Hyperoxygenation reduced inflammatory responses in the hippocampus of Tg-APP/PS1 mice. (A, B) Immunohistochemical images showing GFAP-stained astroglia in the dentate gyrus (A) of wildtype control (WT-CON), wildtype mice exposed to hyperoxygenation $\left(\mathrm{WT}-\mathrm{HO}_{2}\right)$, Tg-APP/PS1 control mice (Tg-CON), and Tg-APP/PS1 mice exposed to hyperoxygenation $\left(\mathrm{Tg}-\mathrm{HO}_{2}\right)$. Bottom panels, high magnification of the boxed areas. GFAP, red; DAPI, blue. Scale bar, $200 \mu \mathrm{m}$. Quantification of the levels by total stained area and stained intensity (B). $\mathrm{n}=7 \sim 9$ animals/group, $4 \sim 8$ repeats. (C, D) Immunohistochemical images showing Iba-1-stained microglia in the dentate gyrus $(\mathrm{C})$ of WT-CON, WT-HO $2, \mathrm{Tg}-\mathrm{CON}$, and Tg-HO 2 mice. Bottom panels, high magnification of the boxed areas. Iba-1, red. Scale bar, $200 \mu \mathrm{m}$. Quantification levels by total stained area (D). $\mathrm{n}=7 \sim 9$ animals/group, 4 8 repeats. (E, F) Photomicrographs showing thioflavin S (ThS)-stained plaques (top panels, green) and Iba-1-stained microglia images (bottom panels, red) merged with ThS (green)-stained plaque images in the dentate gyrus (E) of WT-CON, WT-HO, $\mathrm{Tg}-\mathrm{CON}$, and Tg-HO $\mathrm{H}_{2}$ mice. Scale bar, $200 \mu \mathrm{m}$. Quantification levels of Iba-1-stained areas surrounding ThS-stained plaques (F). $n=8 \sim 9$ animals/group, $4 \sim 6$ repeats. (G, H) Western blot data showing expression levels of p-NFkB, NF-kB (p65), p-p38, p38, GFAP, and Iba-1 in the hippocampus (G) and prefrontal cortex (H) of WT-CON, WT-HO 2 , Tg$\mathrm{CON}$, and $\mathrm{Tg}-\mathrm{HO}_{2}$ mice, and their quantification levels. $\mathrm{n}=6 \sim 8$ animals/group, $5 \sim 10$ repeats. Data are presented as mean \pm SEM. ${ }^{* * *}$ difference between indicated groups. ${ }^{*} \mathrm{p}<0.05 ;{ }^{* *} \mathrm{p}<0.01$ (two-way ANOVA and Bonferroni post hoc test).

HT22 cells, siRNA-mediated knockdown of the Pea3 also reduced the expression of the Mmp-9, whereas the Pea3 knockdown effect on the expression of the Mmp-2, $t P A$, and $u P A$ was subtle or not significantly (Fig. 5C, 5D). The Mecp2 knockdown in HT22 cells did not change Pea3 expression, and conversely, the Pea3 knockdown did not change Mecp2 expression (Fig. 5A 5D). These results suggest that in HT22 neuronal cells, MePC2 can regulate the expression of the Mmp-2 and Mmp-9, and Pea3 can independently regulate the expression of the $\mathrm{Mmp}-9$.

Perfluorodecaline (PFD) is a synthetic compound that has an ability to non-covalently dissolve large amounts of molecular oxygen $\left(\mathrm{O}_{2}\right)$. Therefore, it has been used to provide a hyperoxy- 


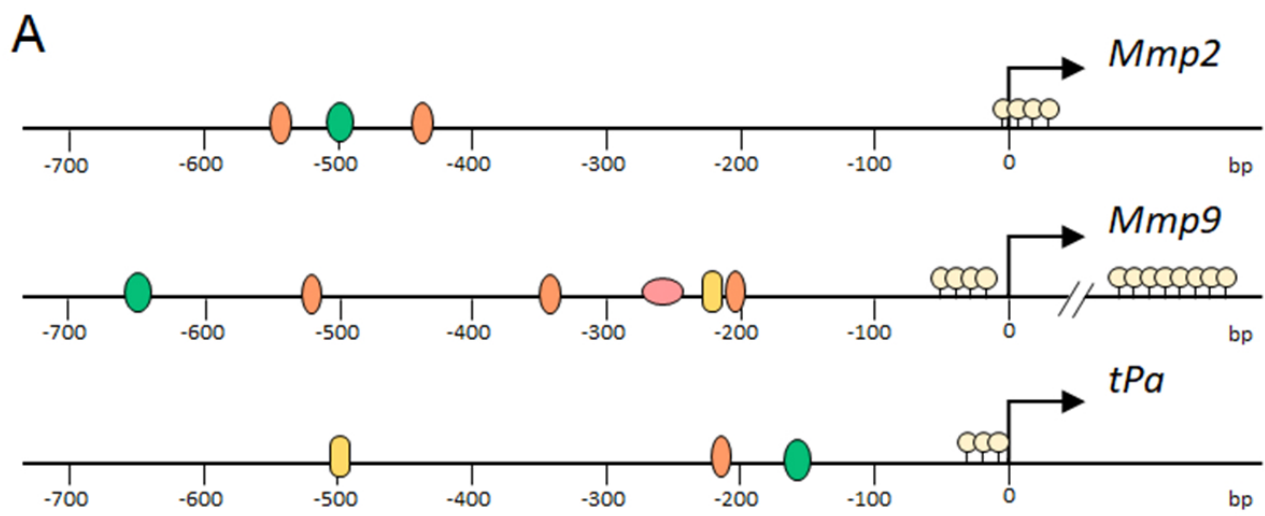

ORunx2 OPea3 ONFkB O STAT Q Cpgisland

B

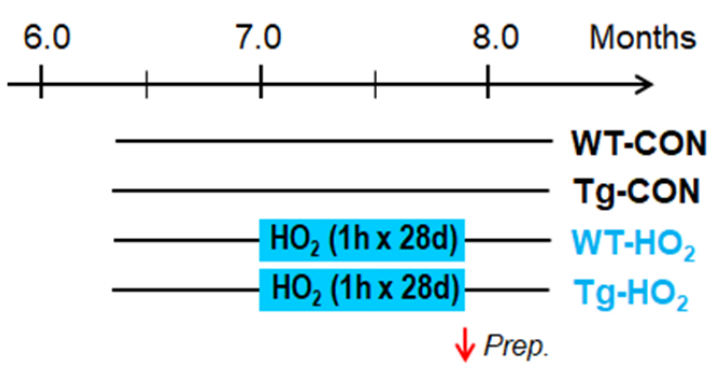

$\mathrm{HO}_{2}: 100 \%, 2.0$ ATA, $1 \mathrm{~h} \times 28 \mathrm{~d}$
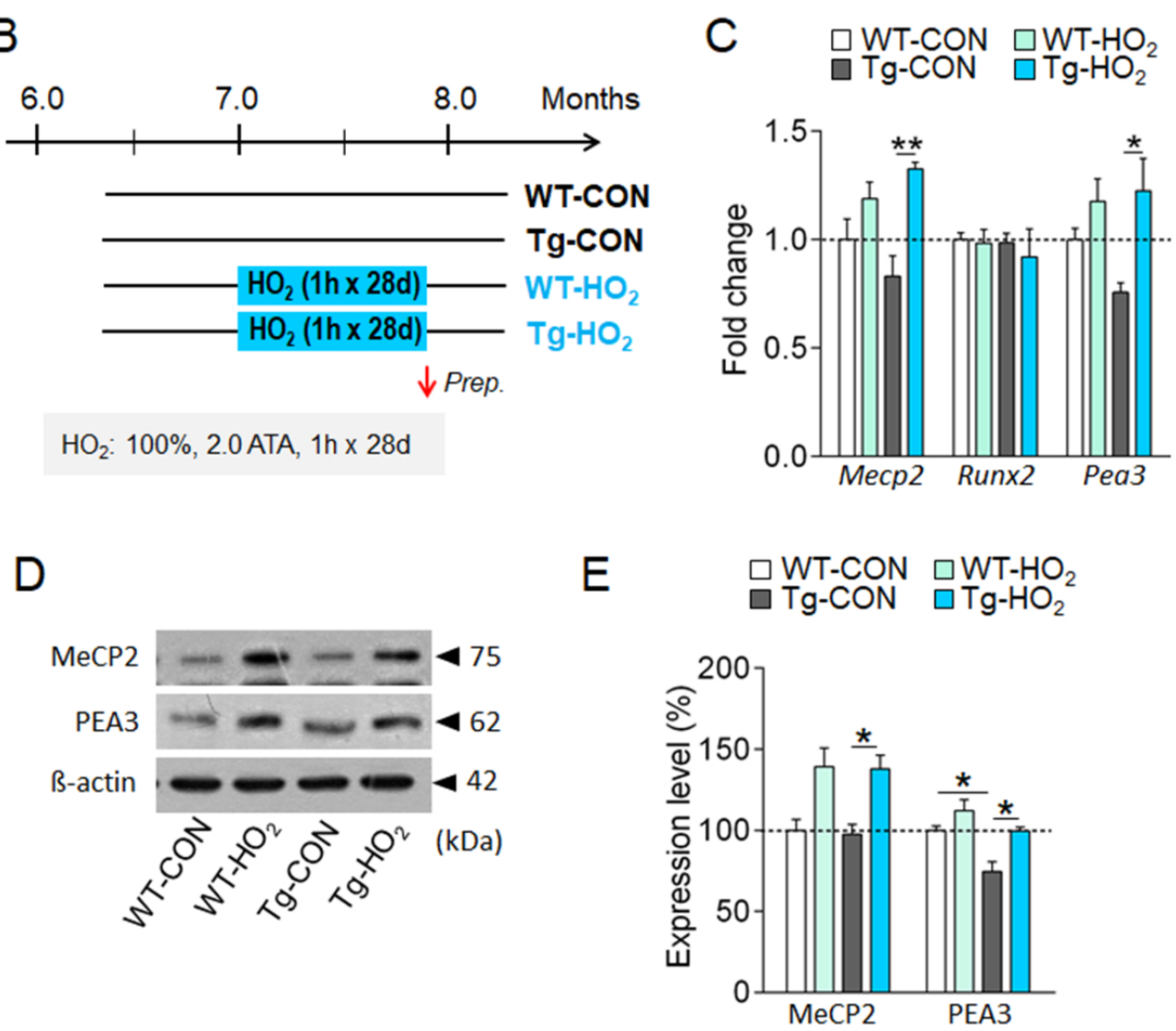

Fig. 4. Hyperoxygenation increased the expression of MeCP2 and Pea3 in the hippocampus of Tg-APP/PS1 mice. (A) The proximal promoter regions of the Mmp-2,Mmp-9, and $t P A$ genes and the locations of known transcription factor binding sites (Runx2, Peas3, NF-kB, STAT) and CpG islands. (B) Experimental design for hyperoxygenation treatment in wildtype and Tg-APP/PS1 mice. $100 \% \mathrm{O}_{2}$ at 2 ATA for 60 min daily for 28 days ( $\mathrm{HO}_{2}$ ). (C) Realtime PCR data showing transcript levels of Mecp2, Runx2, and Pea3 in the hippocampus of WT-CON, WT-HO 2 , Tg-CON, and Tg-HO 2 mice. $\mathrm{n}=8 \sim 9$ animals/group, 4 9 repeats. (D, E) Western blot images showing expression levels of MeCP2 and PEA3 proteins in the hippocampus (D) of WT-CON, $\mathrm{WT}-\mathrm{HO}_{2}, \mathrm{Tg}-\mathrm{CON}$, and Tg- $\mathrm{HO}_{2}$ mice and their quantification levels (E). $\mathrm{n}=6 \sim 9$ animals/group, $3 \sim 7$ repeats. Data are presented as mean $\pm \mathrm{SEM}$. ${ }^{* * *}$ difference between indicated groups. ${ }^{*} \mathrm{p}<0.05$; ${ }^{* *} \mathrm{p}<0.01$ (Student's t-test; one-way ANOVA and Newman-Keuls post hoc test; two-way ANOVA and Bonferroni post hoc test). 

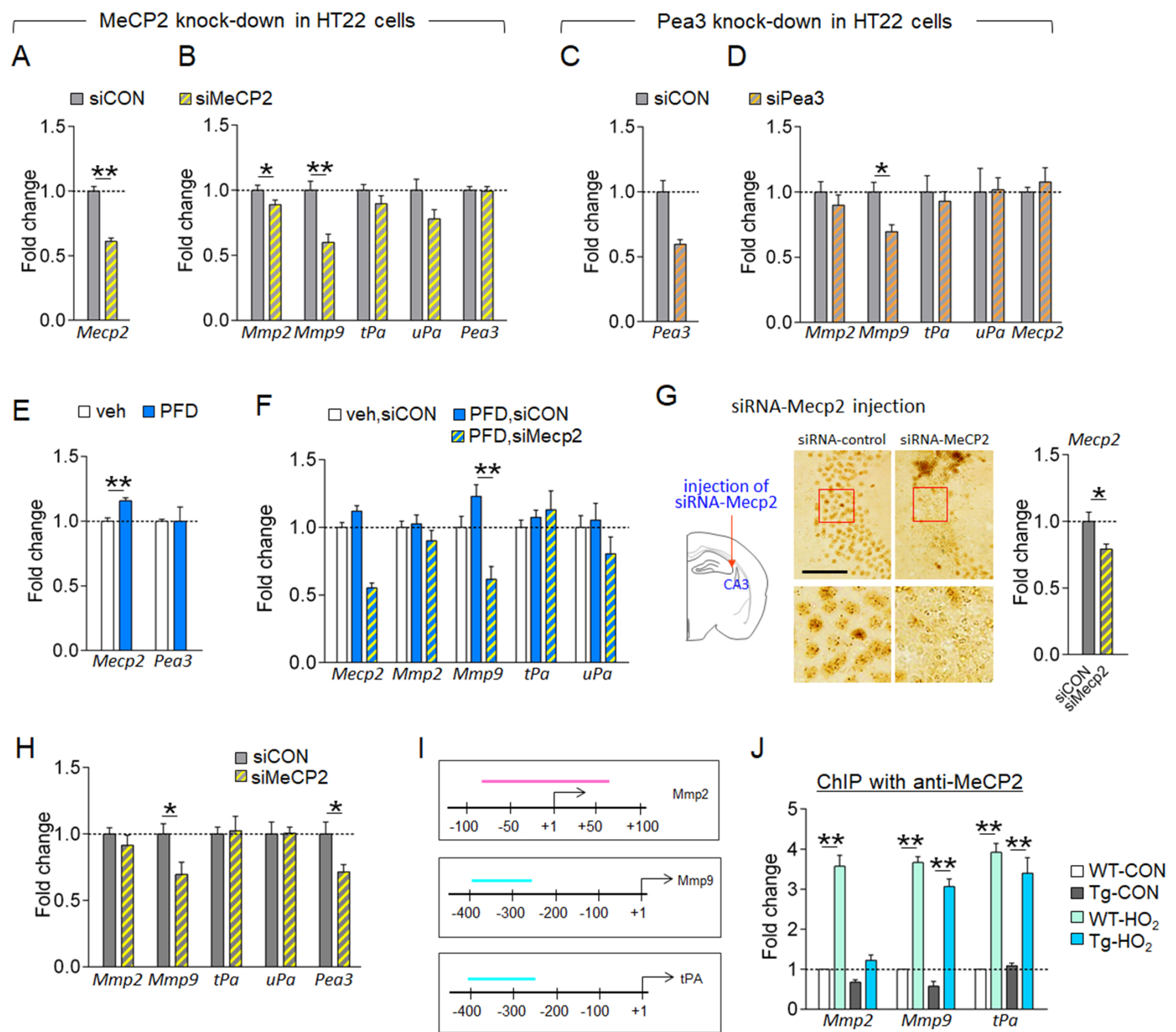

Fig. 5. Hyperoxygenation condition increased the expression of MMP-9 via MeCP2 in HT22 cells. (A D) Expression levels of Mecp2, Pea3, Mmp-2, Mmp-9, $t P A$, and $u P A$ genes in HT22 cells treated with siRNA-MeCP2 (A, B) or siRNA-Pea3 (C, D). siCON, siRNA-control; siMeCP2, siRNA-MeCP2; siPea3, siRNA-Pea3. $\mathrm{n}=6$ wells, $4 \sim 12$ repeats. (E) Expression levels of Mecp2 and Pea3 in HT22 cells treated with 20\% PFD. Veh, vehicle. $\mathrm{n}=6$ wells, $4 \sim 6$ repeats. (F) Expression levels of Mecp2, Mmp-2,Mmp-9, $t P A$, and $u P A$ in HT22 cells treated with 20\% PFD plus siRNA-MeCP2 or siRNA-control. n=6 wells, $5 \sim 7$ repeats. $(\mathrm{G}, \mathrm{H})$ Photomicrographs showing siRNA-mediated knockdown of MeCP2 in the CA3 of mice. High magnification of boxed areas (G, bottom panels). Transcript levels of Mecp2 in siRNA-Mecp2 injection site (G, right). Diagram showing the siRNA-Mecp2 injection site (G, left). Expression levels (H) of the Mmp-2,Mmp-9, tPA, uPA, and Pea3 in siRNA-Mecp2 injection site. siCON, siRNA-control. Scale bar, $20 \mu \mathrm{m}$. $\mathrm{n}=6$ animals/ group, 4 8 repeats. (I, J) The proximal promoter regions (I) of the $M m p-2, M m p-9$, and $t P A$ genes and the locations (the colored bar in each promoter) used for qPCR amplification in ChIP assay. ChIP-qPCR data ( $\mathrm{J}$ ) showing MeCP2 binding levels to the promoter of the Mmp-2, Mmp-9, and $t P A$ in the hippocampus of WT-CON, WT- $\mathrm{HO}_{2}, \mathrm{Tg}-\mathrm{CON}$, and Tg- $\mathrm{HO}_{2}$ mice. $\mathrm{HO}_{2}$ treatment was depicted in Fig. 4B. $\mathrm{n}=7 \sim 11$ animals/group, $5 \sim 6$ repeats. Data are presented as mean \pm SEM. ${ }^{* * *}$ difference between indicated groups. ${ }^{*} \mathrm{p}<0.05 ;{ }^{* *} \mathrm{p}<0.01$ (Student's t-test; one-way ANOVA and Newman-Keuls post hoc test; two-way ANOVA and Bonferroni post hoc test).

genation condition in cell cultures [22]. Supplementing molecular oxygen using PFD in HT22 cells increased the expression of Mecp2, but not Pea3 (Fig. 5E). In PFD-treated HT22 cells, siRNAmediated knockdown of the Mecp 2 suppressed PDF-induced in- creased expression of the Mmp-9, whereas the Mecp 2 knockdown did not significantly change the expression of the Mmp-9, $t P A$ and $u P A$ (Fig. 5F). These results suggest that in HT22 neuronal cells, hyperoxygenation increases the expression of the Mmp- 9 via 


\section{MeCP2.}

Next, we investigated whether MeCP2-dependent changes in the expression of the Mmp-9, Mmp-2, and/or $t P A$ genes occur in vivo. The siRNA-mediated Mecp 2 knockdown in the CA3 region of the hippocampus reduced the expression of the $M m p-9$, whereas the Mecp 2 knockdown effect on the expression of the Mmp-2, $t P A$, and $u P A$ was subtle or insignificant. Interestingly, siRNA-mediated Mecp 2 knockdown in the hippocampus reduced Pea3 expression (Fig. 5G, 5H), which is contrast to the no change of the Pea3 by siRNA-mediated Mecp2 knockdown in HT22 neuronal cells (Fig. $5 \mathrm{~A}, 5 \mathrm{~B})$.

ChIP assay indicated that hyperoxygenation treatment increased the levels of MeCP2 bound to the promoters of the Mmp-2,Mmp9 , and $t P A$ in wildtype and of Tg-APP/PS1 mice (Fig. 5I, 5J).

Together, these results suggest that hyperoxygenation treatment upregulates the expression of the $M m p-2, M m p-9$, and $t P A$ genes in the hippocampus, of which Mmp- 9 expression is regulated by $\mathrm{MeCP} 2$, and Mmp-2 and $t P A$ expression is regulated by MeCP2 and other unknown factors.

\section{DISCUSSION}

In the present study, we demonstrated that hyperoxygenation treatment in Tg-APP/PS1 mice decreased $\beta$-amyloid accumulation in the brain, and that hyperoxygenation treatment in Tg-APP/ PS1 mice revered the reduced expression of MMP-2, MMP-9, and tPA (Fig. 1,2). MMP-2, MMP-9, and tPA are well-known endopeptidases that can degrade $A \beta$ and reduce $\beta$-amyloid toxicity [3537].

The roles of MMP-2 and MMP-9 in AD pathology have been studied in various AD mouse models. In Tg2576 mice, the expression levels of MMP-2, but not MMP-9, were reduced in the hippocampus [31]. In 5xFAD mice, MMP-2 and MMP-9 levels were increased in the hippocampus [38]. In transgenic mice carrying $\operatorname{APP}(\mathrm{K} 670 \mathrm{~N}: \mathrm{M} 671 \mathrm{~L}) / \mathrm{PS} 1(\mathrm{M} 146 \mathrm{~L})$ at 12 18 months of age, MMP-2 and MMP-9 expressions were increased in activated astrocytes surrounding amyloid plaques [39], and pharmacological inhibition of MMP-2 and MMP-9 by infusion of GM6001, an MMP-2/9 inhibitor, via reverse microdialysis elevated A $\beta$ levels [39]. Concerning tPA in AD pathology, tPA expression was increased in the regions surrounding amyloid deposits in the brain of Tg2576 mice [40]. In situ zymography indicated that tPA activity was reduced in the brains of Tg2576 mice and TbCRND8 transgenic mice. Mice lacking the $t P A$ gene showed delayed clearance of $A \beta$ peptides injected in the hippocampus [41]. Administration of recombinant $\mathrm{PA}$ peptides attenuated AD-related pathology by reducing cerebral $\mathrm{A} \beta$ levels and improving cognitive deficits in Tg-APP/PS1 mice [37]. Thus, these results of studies with several AD models suggest that reduced expression of MMP2, MMP-9, and tPA worsens AD pathology, although their detailed underlying mechanisms are complex.

After systematic exploration of cellular factors that potentially regulated $\beta$-amyloid production and clearance following hyperoxygenation treatment, we demonstrated that hyperoxygenation treatment upregulated the expression of MMP-2, MMP-9, and tPA in the hippocampus of Tg-APP/PS1 mice (Fig. 2). Regarding the roles of MMP-2, MMP-9, and tPA in AD pathology, our results support the notion that increased expression of MMP-2, MMP-9, and tPA likely contributes to hyperoxygenation-induced decrease in $\beta$-amyloid accumulation in the brain of Tg-APP/PS1 mice.

The expression of MMP-2, MMP-9 and tPA is regulated by multiple factors associated with $\mathrm{AD}$, which may include aging, stress hormones and the levels of $\beta$-amyloid $[42,43]$. The results of the present study suggest that $\mathrm{MeCP} 2$ has a critical role in regulating MMP-2, MMP-9, and tPA expression under a hyperoxygenation condition. The proximal promoter regions of $\mathrm{Mmp}$ 2, Mmp-9, and $t P A$ genes all contain a stretch of CpG islands, which may serve as biding sites for MeCP2 as summarized (Fig. 4A). In fact, hyperoxygenation treatment increased MeCP2 binding to the proximal promoter of $M m p-2, M m p-9$, and $t P A$ genes (Fig. 5I, 5J). siRNA-mediated knockdown of the Mecp2 in HT22 cells repressed $M m p-9$ expression and, to a lesser extent, $M m p-2$ expression. However, the Mecp 2 knockdown produced insignificant effect on $t P A$ expression in HT22 cells (Fig. 4A 4F). In the hippocampus, siRNA-mediated knockdown of the Mecp2 gene suppressed $M m p-9$, but it produced a nonsignificant or negligible effect on the Mmp-2 and $t P A$ (Fig. 5I, 5J). These results suggest that $M m p-9$ and $M m p-2$ expression is regulated by MeCP 2 in neuronal cells, whereas $t P A$ expression are regulated by other factors which need to be studied in the future.

MeCP2 knockdown in HT22 cells did not change Pea3 expression (Fig. 5A, 5B). However, MeCP2 knockdown in the hippocampus reduced Pea3 expression (Fig. G and H). These results suggest that MeCP2 might regulate Pea3 in non-neuronal cells. Pea3 is a transcription factor that is expressed in neurons and astroglia in the hippocampus [44]. Pea3 regulated $\mathrm{Mmp}^{-9}$ expression in neuronal cells (Fig. 5C, 5D). MMP-9 is also expressed in neurons and astroglia $[38,39]$. MMP-2 is detected in astroglia and a subset of pyramidal neurons [45]. These diverse combinations of MeCP2, Pea3, MMP-2, and MMP-9 expression in different cell types raise the question of whether MMP-2, MMP-9, and tPA expressions are differentially regulated by $\mathrm{MeCP} 2$ and/or Pea3 in different cell types. Regarding that siRNA-mediated knockdowns of MeCP2 in HT22 cells and in the hippocampus were not complete (Fig. 5A, 
$5 G)$, it might be important to further investigate whether the difference in Mecp2 knockdown effects on Pea3 between HT22 cells (Fig. 5A, 5B) and hippocampus (Fig. 5G, 5H) is related to differential expression of $\mathrm{MeCP} 2$ and Pea3 in neuronal and non-neuronal types. It is also possible that hyperoxygenation-induced upregulation of MMP-9 is regulated by MeCP2, whereas hyperoxygenation-induced upregulation of MMP-2 and tPA requires MeCP2 and other factors that need to be studied in the future.

Hyperoxygenation is known to increase oxidative stress [46]. Several lines of evidence suggest that oxidative stress is required for therapeutic effects of hyperoxygenation $[46,47]$. N-acetylcysteine treatment during hyperoxygenation blocked the proliferation effects of hyperoxygenation on bone marrow-derived stem cells [48] and the wound healing effects of hyperoxygenation in ischemic would tissue [49]. In Tg-APP/PS1 mice, hyperoxygenation treatment at 2.0 ATA daily for $1 \mathrm{~h}$ for 28 days suppressed the levels of $\mathrm{A} \beta 42$ accumulation and plaque disposition, and also reduced the increased ROS levels in the hippocampus [22]. Furthermore, repeated hyperoxygenation treatment increases antioxidant enzymes in the brain [22]. These results suggest that repeated hyperoxygenation treatment activates the cellular factors that reduce oxidative stress. Regarding that oxidative stress is a risk factor aggravating neuropathology in AD brains, properly controlled hyperoxygenation treatment procedures need to be developed.

\section{ACKNOWLEDGEMENTS}

This research was supported by a grant (2021R1A2B5B02002245) from the Ministry of Science, ICT and Future Planning, Republic of Korea.

\section{REFERENCES}

1. Ballard C, Gauthier S, Corbett A, Brayne C, Aarsland D, Jones E (2011) Alzheimer's disease. Lancet 377:1019-1031.

2. Serrano-Pozo A, Frosch MP, Masliah E, Hyman BT (2011) Neuropathological alterations in Alzheimer disease. Cold Spring Harb Perspect Med 1:a006189.

3. DeTure MA, Dickson DW (2019) The neuropathological diagnosis of Alzheimer's disease. Mol Neurodegener 14:32.

4. Barnes DE, Yaffe K (2011) The projected effect of risk factor reduction on Alzheimer's disease prevalence. Lancet Neurol 10:819-828.

5. Masters CL, Bateman R, Blennow K, Rowe CC, Sperling RA, Cummings JL (2015) Alzheimer's disease. Nat Rev Dis Primers 1:15056.

6. Hou Y, Dan X, Babbar M, Wei Y, Hasselbalch SG, Croteau DL,
Bohr VA (2019) Ageing as a risk factor for neurodegenerative disease. Nat Rev Neurol 15:565-581.

7. Sonntag WE, Eckman DM, Ingraham J, Riddle DR (2007) Regulation of cerebrovascular aging. In: Brain aging: models, methods, and mechanisms. (Riddle DR, ed), pp 279-304. CRC Press/Taylor \& Francis, Boca Raton (FL).

8. Brown WR, Thore CR (2011) Review: cerebral microvascular pathology in ageing and neurodegeneration. Neuropathol Appl Neurobiol 37:56-74.

9. Ambrose CT (2017) Pro-angiogenesis therapy and aging: a mini-review. Gerontology 63:393-400.

10. Moeini M, Lu X, Avti PK, Damseh R, Bélanger S, Picard F, Boas D, Kakkar A, Lesage F (2018) Compromised microvascular oxygen delivery increases brain tissue vulnerability with age. Sci Rep 8:8219.

11. Kisler K, Nelson AR, Montagne A, Zlokovic BV (2017) Cerebral blood flow regulation and neurovascular dysfunction in Alzheimer disease. Nat Rev Neurosci 18:419-434.

12. Göttler J, Preibisch C, Riederer I, Pasquini L, Alexopoulos P, Bohn KP, Yakushev I, Beller E, Kaczmarz S, Zimmer C, Grimmer T, Drzezga A, Sorg C (2019) Reduced blood oxygenation level dependent connectivity is related to hypoperfusion in Alzheimer's disease. J Cereb Blood Flow Metab 39:13141325.

13. Solis E Jr, Hascup KN, Hascup ER (2020) Alzheimer's disease: the link between amyloid- $\beta$ and neurovascular dysfunction. J Alzheimers Dis 76:1179-1198.

14. Egashira N, Iwasaki K, Ishibashi M, Hatip-Al-Khatib I, Wolozin B, Mishima K, Irie K, Fujiwara M (2002) Hypoxia enhances beta-amyloid-induced apoptosis in rat cultured hippocampal neurons. Jpn J Pharmacol 90:321-327.

15. Titus AD, Shankaranarayana Rao BS, Harsha HN, Ramkumar K, Srikumar BN, Singh SB, Chattarji S, Raju TR (2007) Hypobaric hypoxia-induced dendritic atrophy of hippocampal neurons is associated with cognitive impairment in adult rats. Neuroscience 145:265-278.

16. Vieira M, Fernandes J, Carreto L, Anuncibay-Soto B, Santos M, Han J, Fernández-López A, Duarte CB, Carvalho AL, Santos AE (2014) Ischemic insults induce necroptotic cell death in hippocampal neurons through the up-regulation of endogenous RIP3. Neurobiol Dis 68:26-36.

17. Zhang X, Le W (2010) Pathological role of hypoxia in Alzheimer's disease. Exp Neurol 223:299-303.

18. Montagne A, Nation DA, Pa J, Sweeney MD, Toga AW, Zlokovic BV (2016) Brain imaging of neurovascular dysfunction in Alzheimer's disease. Acta Neuropathol 131:687-707.

19. Bu XL, Liu YH, Wang QH, Jiao SS, Zeng F, Yao XQ, Gao D, 
Chen JC, Wang YJ (2015) Serum amyloid-beta levels are increased in patients with obstructive sleep apnea syndrome. Sci Rep 5:13917.

20. Zetterberg H, Mörtberg E, Song L, Chang L, Provuncher GK, Patel PP, Ferrell E, Fournier DR, Kan CW, Campbell TG, Meyer R, Rivnak AJ, Pink BA, Minnehan KA, Piech T, Rissin DM, Duffy DC, Rubertsson S, Wilson DH, Blennow K (2011) Hypoxia due to cardiac arrest induces a time-dependent increase in serum amyloid $\beta$ levels in humans. PLoS One 6:e28263.

21. Shapira R, Efrati S, Ashery U (2018) Hyperbaric oxygen therapy as a new treatment approach for Alzheimer's disease. Neural Regen Res 13:817-818.

22. Choi J, Kwon HJ, Lee JE, Lee Y, Seoh JY, Han PL (2019) Hyperoxygenation revitalizes Alzheimer's disease pathology through the upregulation of neurotrophic factors. Aging Cell 18:e12888.

23. Shapira R, Solomon B, Efrati S, Frenkel D, Ashery U (2018) Hyperbaric oxygen therapy ameliorates pathophysiology of 3xTg-AD mouse model by attenuating neuroinflammation. Neurobiol Aging 62:105-119.

24. Wang DS, Dickson DW, Malter JS (2006) beta-Amyloid degradation and Alzheimer's disease. J Biomed Biotechnol 2006:58406.

25. Kurz A, Perneczky R (2011) Amyloid clearance as a treatment target against Alzheimer's disease. J Alzheimers Dis 24 Suppl 2:61-73.

26. Baranello RJ, Bharani KL, Padmaraju V, Chopra N, Lahiri DK, Greig NH, Pappolla MA, Sambamurti K (2015) Amyloid-beta protein clearance and degradation $(\mathrm{ABCD})$ pathways and their role in Alzheimer's disease. Curr Alzheimer Res 12:3246.

27. Ries M, Sastre M (2016) Mechanisms of $A \beta$ clearance and degradation by glial cells. Front Aging Neurosci 8:160.

28. Jankowsky JL, Slunt HH, Ratovitski T, Jenkins NA, Copeland NG, Borchelt DR (2001) Co-expression of multiple transgenes in mouse CNS: a comparison of strategies. Biomol Eng 17:157-165.

29. Savonenko A, Xu GM, Melnikova T, Morton JL, Gonzales V, Wong MP, Price DL, Tang F, Markowska AL, Borchelt DR (2005) Episodic-like memory deficits in the APPswe/PS1dE9 mouse model of Alzheimer's disease: relationships to betaamyloid deposition and neurotransmitter abnormalities. Neurobiol Dis 18:602-617.

30. Kim HR, Kim JH, Choi EJ, Lee YK, Kie JH, Jang MH, Seoh JY (2014) Hyperoxygenation attenuated a murine model of atopic dermatitis through raising skin level of ROS. PLoS One 9:e109297.

31. Lee KW, Kim JB, Seo JS, Kim TK, Im JY, Baek IS, Kim KS, Lee JK, Han PL (2009) Behavioral stress accelerates plaque pathogenesis in the brain of Tg2576 mice via generation of metabolic oxidative stress. J Neurochem 108:165-175.

32. Choi J, Kim JE, Kim TK, Park JY, Lee JE, Kim H, Lee EH, Han PL (2015) TRH and TRH receptor system in the basolateral amygdala mediate stress-induced depression-like behaviors. Neuropharmacology 97:346-356.

33. Che Y, Yu YM, Han PL, Lee JK (2001) Delayed induction of p38 MAPKs in reactive astrocytes in the brain of mice after KA-induced seizure. Brain Res Mol Brain Res 94:157-165.

34. Lee JE, Kwon HJ, Choi J, Han PL (2019) Stress-induced epigenetic changes in hippocampal Mkp-1 promote persistent depressive behaviors. Mol Neurobiol 56:8537-8556.

35. Backstrom JR, Lim GP, Cullen MJ, Tökés ZA (1996) Matrix metalloproteinase-9 (MMP-9) is synthesized in neurons of the human hippocampus and is capable of degrading the amyloid-beta peptide (1-40). J Neurosci 16:7910-7919.

36. Hernandez-Guillamon M, Mawhirt S, Blais S, Montaner J, Neubert TA, Rostagno A, Ghiso J (2015) Sequential amyloid- $\beta$ degradation by the matrix metalloproteases MMP-2 and MMP-9. J Biol Chem 290:15078-15091.

37. ElAli A, Bordeleau M, Thériault P, Filali M, Lampron A, Rivest S (2016) Tissue-plasminogen activator attenuates Alzheimer's disease-related pathology development in APPswe/PS1 mice. Neuropsychopharmacology 41:1297-1307.

38. Py NA, Bonnet AE, Bernard A, Marchalant Y, Charrat E, Checler F, Khrestchatisky M, Baranger K, Rivera S (2014) Differential spatio-temporal regulation of MMPs in the 5xFAD mouse model of Alzheimer's disease: evidence for a pro-amyloidogenic role of MT1-MMP. Front Aging Neurosci 6:247.

39. Yin KJ, Cirrito JR, Yan P, Hu X, Xiao Q, Pan X, Bateman R, Song H, Hsu FF, Turk J, Xu J, Hsu CY, Mills JC, Holtzman DM, Lee JM (2006) Matrix metalloproteinases expressed by astrocytes mediate extracellular amyloid-beta peptide catabolism. J Neurosci 26:10939-10948.

40. Lee JY, Kweon HS, Cho E, Lee JY, Byun HR, Kim DH, Kim YH, Han PL, Koh JY (2007) Upregulation of tPA/plasminogen proteolytic system in the periphery of amyloid deposits in the Tg2576 mouse model of Alzheimer's disease. Neurosci Lett 423:82-87.

41. Melchor JP, Pawlak R, Strickland S (2003) The tissue plasminogen activator-plasminogen proteolytic cascade accelerates amyloid-beta (Abeta) degradation and inhibits Abetainduced neurodegeneration. J Neurosci 23:8867-8871.

42. Wang XX, Tan MS, Yu JT, Tan L (2014) Matrix metallo- 
proteinases and their multiple roles in Alzheimer's disease. Biomed Res Int 2014:908636.

43. Brkic M, Balusu S, Libert C, Vandenbroucke RE (2015) Friends or foes: matrix metalloproteinases and their multifaceted roles in neurodegenerative diseases. Mediators Inflamm 2015:620581.

44. Kandemir B, Davis S, Yiğit EN, Öztürk G, Yllmaz B, Laroche S, Kurnaz IA (2020) Expression of Pea3 protein subfamily members in hippocampus and potential regulation following neuronal stimulation. Neurosci Lett 738:135348.

45. Ulrich R, Gerhauser I, Seeliger F, Baumgärtner W, Alldinger S (2005) Matrix metalloproteinases and their inhibitors in the developing mouse brain and spinal cord: a reverse transcription quantitative polymerase chain reaction study. Dev Neu- rosci 27:408-418.

46. Thom SR (2009) Oxidative stress is fundamental to hyperbaric oxygen therapy. J Appl Physiol (1985) 106:988-995.

47. Mach WJ, Thimmesch AR, Pierce JT, Pierce JD (2011) Consequences of hyperoxia and the toxicity of oxygen in the lung. Nurs Res Pract 2011:260482.

48. Milovanova TN, Bhopale VM, Sorokina EM, Moore JS, Hunt TK, Hauer-Jensen M, Velazquez OC, Thom SR (2009) Hyperbaric oxygen stimulates vasculogenic stem cell growth and differentiation in vivo. J Appl Physiol (1985) 106:711-728.

49. Zhang Q, Gould LJ (2014) Hyperbaric oxygen reduces matrix metalloproteinases in ischemic wounds through a redoxdependent mechanism. J Invest Dermatol 134:237-246. 